\title{
Green Neighborhood Standards from a Planning Perspective: The LEED for Neighborhood Development (LEED-ND)
}

ELISSA BLACK

Elissa Black is currently completing her Master's in City and Regional Planning at Cal Poly, San Luis Obispo. Her research interests include green neighborhood design, affordable housing, and the use of Geographic Information Systems (GIS) in regional land use planning.

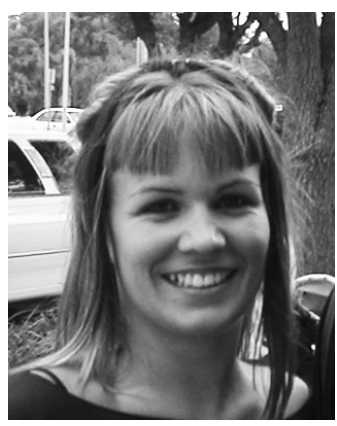

The US Green Building Council's LEED (Leadership in Energy and Environmental Design) national system became the country's prominent promoter of green design practices. In expanding their approach towards environmental sustainability, the GBC is now developing standards for neighborhood development. In this essay, Elissa Black discusses these important issues and their implications for planning practice, giving us a hint of the master's project she is currently developing.

\footnotetext{
"The development community will play an increasingly key role in slowing climate change. Shrinking household size, marathon commutes, and cultural preferences are boosting the demand for compact, walkable neighborhoods." -Michael Davidson, manager of the Campaign for Sensible Growth (Stromberg, 2007, p.53)
}

The Leadership in Energy and Environmental Design (LEED) is a national rating system developed by the United States Green Building Council (USGBC). The LEED rating system certifies development projects based on sustainability criteria. Prior to 2007 LEED certified only individual buildings. A new LEED rating system has emerged, LEED for Neighborhood Development (LEED-ND), which is intended to certify development projects that consist of anywhere from a series of buildings to entire neighborhoods (Javid, 2007). LEED-ND was developed by a partnership of the USGBC, the Congress for New Urbanism and the Natural Resources Defense Council (NRDC). The new LEEDND rating system may have far reaching potential to encourage the greening of entire neighborhood developments and master planned communities.

In 2007, the LEED-ND pilot program commenced with 238 participants, but the official rating system is not expected to launch until early 2009. As of August 2007, the state of Illinois had enacted legislature that will provide financial incentives for private development projects that are LEED-ND certified (Stromberg, 2007). "The act is attractive to legislators and developers because it is nonregulatory and offers incentives for creating these types of communities without imposing government standards" (Stromberg 2007: 53). A new city in North Korea, New Songdo City, is using LEED-ND standards to guide the development of the entire city (Clements, 2007). The new rating system has gained worldwide popularity. But, as LEED-ND is still in its infancy, there are bound to be issues that arise regarding its effectiveness as a national set of development standards intended to generate green neighborhood development.

\section{Background: The Evolution of LEED Rating Systems}

The USGBC was formed as a coalition of building-related organizations who sought a forum to consider the economic, environmental, and social costs and benefits generated by design and construction options (Soloman, 2005). The USGBC piloted the first green-building rating system, LEED for New Construction and Major Renovations (LEED-NC), in 1999, which certified individual buildings based on specific green building standards. By March 2000, version 2.0 of LEED-NC was publicly launched.

One of the original missions of the USGBC in implementing this new tool was to help transform the building and real estate markets (Soloman, 2005). Since the inception of LEED, renewable green 
building resources and materials have become more widely available and more competitive than they ever were (Kirk, 2006). The real estate market has also been affected as green building features, valued by consumers for their economic efficiency in utilities and environmental friendliness, are used as marketing tools. LEED has greatly impacted the building and real estate markets: " [LEED] helps to ensure that users and buyers receive the environmental benefits they pay for, giving green building practices credibility in corporate America" (Kirk, 2006: 73).

The success with LEED-NC led the USGBC to create additional rating systems for various aspects of buildings, such as commercial interiors (LEED-CI), core and shell (LEED-CS), and existing building operations and maintenance (LEED-EB). The latest additions have been LEED for homes (LEED-H), and LEED-ND. The LEED-ND pilot program was released in early 2007 and derives many of its standards from the most recently updated version of LEED-NC. It became apparent to many in the green building industry that a green building was not really 'green' if it wasn't located with respect to its regional context, in its relation to other buildings, housing, transportation, and services.

To create a LEED rating system that would consider multiple buildings or whole neighborhoods within their greater context, the LEED-ND team formulated a rating system that would be made up of four major categories: Smart Location and Linkage, Neighborhood Pattern and Design, Green Construction and Technology, and Innovation and Design Process. The scope of LEED-ND is much larger than previous rating systems to include not only environmental concerns, but social issues as well. For example, as an incentive to developers to provide a diversity of housing types and affordability in their project, $10 \%$ of the total Neighborhood Pattern and Design points available are offered for diverse and affordable housing.

The LEED rating system has grown to be the most recognized green building assessment tool in the United States (Muse, 2006). Across the country various architecture, landscape architecture, and planning firms boast that they have the most LEED Accredited Professionals (AP) employed within their city limits, state, or even country. In an online report by Building Design and Construction, 50 of the nation's top design firms were ranked according to the number of LEED APs employed within their firm. The list totaled 40,000 LEED APs as of July, 2007, working in private firms across the nation. The firms at the top of the list who employed the most LEED APs (not as a percentage of total employed, but in raw numbers) were Perkins+Will, Gensler, HOK, Stantec, and the Turner Corp (Barista, 2007).

The LEED rating system has already made a significant imprint on the development world and it has continued to evolve over time, but it is far from perfect. LEED is praised as the driving force behind major changes in the real estate and building markets to make green building materials and resources more competitive (Kirk, 2006). However, along with the many praises for the rating system, LEED has been criticized for several reasons as follows.

\section{Issues with the LEED Certification Process}

As process can be just as important to the success of an 'implementation tool' as the tool itself, two main concerns with the LEED certification process have been identified in recent literature.

One of the most common criticisms is that the LEED certification process is too expensive. Depending on the size of a project the cost to register with the USGBC to acquire LEED certification can be very expensive (Kuzyk, 2006; Solomon, 2005; Schendler, Udall, 2005). In July 2007, more than 370 LEED-ND pilot program applications were received by the USGBC. Of those, 238 applicants paid 
anywhere from $\$ 8,000$ to $\$ 20,000$ to the USGBC to officially register their project for the certification process. What happened to the other 138 that didn't register for the pilot program? Could a high registration fee deter developers from pursuing certification for their 'green' project?

"The danger is that LEED certification will cannibalize funds that otherwise could be used to improve a building. Developers face a choice: pursue LEED - or purchase a photovoltaic system, daylighting, or efficiency upgrades" (Schendler \& Udall, 2005: 2).

The second criticism of the LEED process is that it is too complex, time consuming, and bureaucratic (Soloman, 2005; Muse, 2006; Schendler \& Udall, 2005). A recent article that discusses an analysis by the National Association of Home Builders states that "most [LEED-ND] applicants in most instances would have to go through more than 200 steps to complete the application process" (NAHB, 2007).

\section{Issues with the Effectiveness of LEED Standards}

The following issues regarding the effectiveness of LEED standards to generate green projects have been identified: the financial feasibility of building green, the lack of life-cycle analysis of building techniques and materials, and the regional and contextual inappropriateness of a set of national development standards--the 'one size fits all' conundrum. The financial feasibility of building green may not be directly affected by the USGBC alone; other market related factors that the USGBC has no control over affect the costs of building green. LEED has had a history of influencing the green building market by helping to drive the competitiveness of green building materials, which is beneficial for the green building market. But, the USGBC must balance that with their responsibility to set forth standards that are reasonable for developers and builders to achieve. If LEED standards incur unreasonable and excessive costs to developers, then only very few development projects can be certified under the LEED system, which results in limited participation in the program. To ensure that more projects can participate and more diversity can exist, LEED standards must be reasonable for developers to pursue.

Currently, the debate as to whether building green is more expensive than traditional building is a hot topic among builders, developers, and designers. On one side, the argument is made that the reality of building green is that it is much more expensive than conventional building and therefore less feasible (Schendler, 2005), while others claim that there is no significant difference in the average cost of green buildings versus non-green buildings (Langdon, 2007).

The second concern regarding LEED standards is that it currently does not take into account lifecycle analysis, or "the scientific discipline of measuring resources and energy consumed, and the environmental impact created by a particular product throughout its life" (Soloman, 2005:, p. 138). Given that LEED is set up to award one point per credit, it does not give incentive for building strategies that utilize the least environmentally damaging materials; the same amount of points are awarded among different strategies that vary in environmental impact. A more sophisticated system would allow for a range of points within each credit, based on life cycle analysis of the different materials (Soloman, 2005).

The third, and perhaps most important issue in terms of implementing successful green neighborhood development standards, is the issue of regional and contextual appropriateness. LEED has been frequently criticized as a set of broad national standards that are bioregionally insensitive. In the case of climate differences, which affect the use of water, "water conservation is more of a priority in hot, 
dry climates, yet the USGBC awards the same number of credits for water conservation in Seattle as in Phoenix" (Soloman, 2005: 3).

If, in some cases, LEED can be bioregionally insensitive, how does it fair in its sensitivity to other site-specific circumstances? Though not yet supported by substantial research, the supposition has been made that some LEED credits are not appropriate for certain contexts. The USGBC certifies a building based on verification that it is achieving the intended objectives set forth by the LEED rating system and it is assumed that the LEED credits pursued are beneficial to the environment. But, there has been some evidence suggesting that, in limited cases, unintended consequences have resulted in LEED certified projects that "inadvertently fail to benefit the environment" (Bray \& McCurry, 2006). In two cases, Bray and McCurry (2006) found that, because projects were so intent on acquiring LEED certification, they actually pursued credits that didn't produce a sustainable outcome in the specific context of their project.

In one case, involving a 'sustainable sites' credit, the applicant built bicycle storage and change/ shower facilities into the project in order to achieve the 'alternative transportation' credit. The credit is intended to encourage building occupants and users to bicycle as a means of transportation to and from the site, but, because this specific site was in a rural area within a state park and located on a mountaintop, it was not conducive to bicycle access. Thus, the credit's intent was not achieved; employees still used gas-powered vehicles as their mode of transportation to and from the building. In addition, the construction of shower/change facilities and installation of bike racks was a wasteful use of building resources since they are not used, thus creating a negative environmental impact instead of a positive one (Bray \& McCurry, 2006). This is one example of how developers may pursue LEED credits as a means of getting their project certified even if it requires implementing building criteria that aren't appropriate for their project site and could result in hurting the environment.

[The] USGBC developed a simple, universal system in which one goal, or credit, receives one point... USGBC volunteers "knew that it was clumsy and limited, and many wanted to wait until it could be put on more scientific footing, but more wanted to get something out quickly." Berkebile continues, "What was shocking was that many agencies and cities so quickly embraced it as their tool, not realizing that it was not regional, did not do life-cycle analysis, and was focused on corporate buildings. (Soloman, 2005:, p. 138)

\section{Effectiveness of LEED-ND: What is "Green Neighborhood Development"?}

To better understand how LEED-ND might be an effective tool for developers to build, and municipalities to encourage green neighborhood developments, it is crucial to understand what LEED-ND intends to do and how the rating system defines 'green neighborhood development.' Each of the three major components of LEED-ND articulate different objectives related to green development.

The Green Construction and Technology component is intended to reduce the environmental impact of buildings; most of its criteria are based on the original LEED-NC green building standards. Therefore, criticisms and praise of LEED-NC standards, such as those offered above, are applicable to evaluation of LEED-ND's Green Construction and Technology component. As for the other two components of LEED-ND, Smart Location and Linkage and Neighborhood Pattern and Design are comprised of standards that relate to the neighborhood's scale of development. Thus, their standards constitute the gist of how LEED-ND defines green neighborhood development. 
The Smart Location and Linkage criteria defines green neighborhood development as urban infill, brownfield redevelopment, or largely urban oriented development (Javid, 2007). A logical and valid effort to combat unsustainable sprawl and greenfield development, its pre-requisite could be problematic for some projects that may not be truly urban but may not be contributing to sprawl either. Neighborhood development projects in semi-rural areas that may strive to be "green" through pursuing LEED-ND criteria may find the Smart Location and Linkage pre-requisite difficult to obtain (NAHB, 2007). A potential challenge for developers and the USGBC is how to define green neighborhood development in terms of urban versus rural contexts.

In other aspects of neighborhood development related to urban design, specific design concepts that have gained popularity lately have been identified as being sustainable or green. Some of these concepts have their roots in traditional neighborhood design and the urban design principles set forth by The Congress for New Urbanism. Research that provides a critical analysis of New Urbanist design principles is relevant to the critique of LEED-ND, as the Congress for New Urbanism is a LEED-ND partner responsible for drafting the LEED-ND pilot program standards. For example, the Neighborhood Pattern and Design component promotes the idea of creating "community" by implementing specific traditional neighborhood design standards, the outcome of which has been a topic of recent debate among New Urbanism critics (Brain, 2005; Nasar, 2003).

Studies have also been conducted that examine the effectiveness of managing transportation demand by designing neighborhoods that contain mixed uses and encourage alternative modes of transportation, another traditional neighborhood concept that is put forth in LEED-ND standards.

It is evident that LEED-ND has already become an accepted set of development standards by many, even while the program has yet to officially launch. It is conceivable that LEED-ND, being so new, is not ready to be widely implemented without first discovering whether or not it works properly. Identifying the strengths and weaknesses of the program is a necessary step before adopting it as our own set of standards.

\section{Conclusion}

Studies that offer a critical analysis of the LEED-ND certification process are needed to better understand concerns regarding the significance of the cost of the LEED certification process and difficulty that comes with overly bureaucratic process. In addition, it will be crucial in this phase of the LEED-ND pilot program to analyze the robustness of its standards in generating green neighborhood development. Special attention should be given to the concern that LEED-ND is a broad set of national standards that are not tailored to meet the specific needs of different regions or site contexts.

A case study strategy that would follow a development project through the certification process and track its success in using the LEED-ND standards may be one method to generate this analysis. For my Master's in City and Regional Planning professional project I will be using such a case study methodology to critically analyze LEED-ND process and standards from a planning perspective to better understand the possibilities and challenges of green neighborhood development. The primary case will be a neighborhood development project located in Paso Robles, California, a semi-rural community in the Central Coast region. The project, "River Oaks, the Next Chapter," is 270 acres of mixed uses, including residential, recreational, and commercial. The case study will be conducted in two phases: first, by preparing LEED-ND certification documents for the project, and second, by reviewing the results of the process through a review committee and analyzing the outcome in relation 
to selected comparable projects. The review phase will involve the formation of a review committee made up of local LEED APs, academics, and planning / urban design professionals. The review committee will be asked to evaluate "River Oaks" in terms of green neighborhood development.

LEED-ND has great potential to influence the world of planning and development. The USGBC recognizes the evolutionary nature of developing LEED standards. The more the LEED rating systems are put to the test, the more constructive criticism can be offered to improve them for the future. The results of my investigation may contribute to a better understanding of the impacts of the LEED-ND in the development of greener and more sustainable communities.

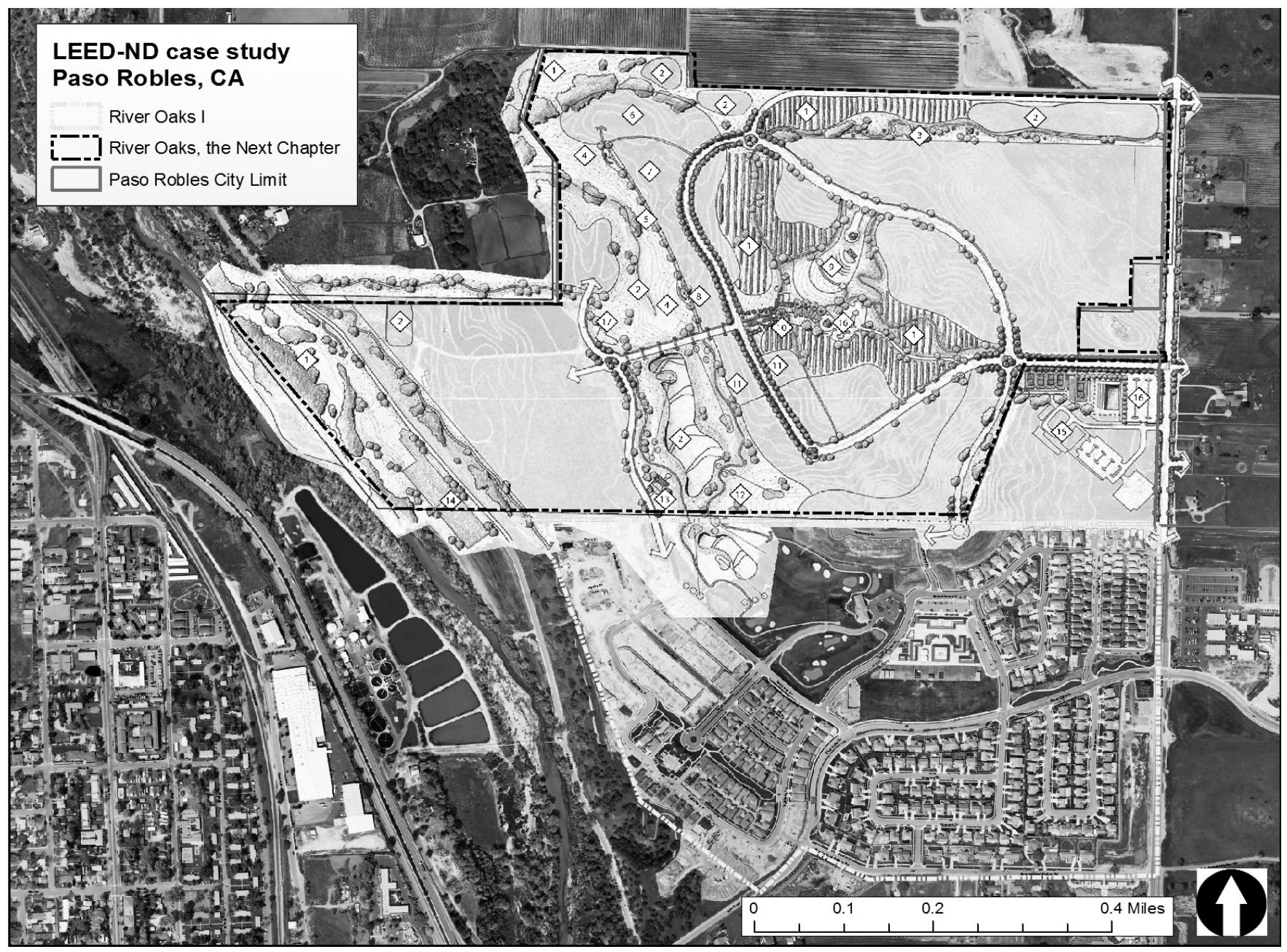

Figure 1

The case-study. Paso Robles, River Oaks I, and the illustrative master plan of River Oaks, the Next Chapter. (courtesy Estrella Associates) 


\section{References:}

Barista, Dave. (2007). 40,000 LEED APs and Counting. Building Design and Construction, Retrieved October 20, 2007 from: http://www.bdcnetwork.com/article/CA6459403.html

Brain, D. (2005). From good neighborhoods to sustainable cities: Social science and the social agenda of the new urbanism. International Regional Science Review, 28(2), 217-238. Retrieved September 19, 2007, from Urban Studies \& Planning: A SAGE Full-Text Collection database.

Bray, J., Natasha, M. (2006). Unintended consequences: how the use of LEED can inadvertently fail to benefit the environment. Journal of Green Building 1(4), 152-165.

Clements, J. (July, 2007). New Songdo City Enters USGBC Pilot Program. Retrieved December 2, 2007 from: http://www.usgbc.org/News/USGBCInTheNewsDetails.aspx?ID=3299

Javid, David. (2007). LEED-ND is coming: are you ready? How to implement green planning and design principles now. APA California Planner, March-April, 13-16.

Kirk, P. (2006). Designing the way to green: environmental design is now synonymous with sustainable, or green, design. Urban Land 65(11-12), 73-79.

Muse, A. , Plaut, J.M. (2006) An inside look at LEED: experienced practitioners reveal the inner workings of LEED. Journal of Green Building 1(1), 3-8.

NAHB. (2007). New LEED certification for development found wanting. Retrieved November 1, 2007 from: http://www.nahb.org/news_details.aspx?sectionID=206\&newsID=5612

Newberg, S. (2005). Certifying neighborhoods: LEED-ND could have far-reaching effects on the development industry. Urban Land 64 (10), p11-12, p.32,35.

Newton, M.W. (2005). Green evolution: the next step is the adoption of more fundamental shifts in design and engineering. Urban Land 64(10), 38,40.

Schendler, A., Udall, R. (2005). LEED is broken - Let's Fix it. Retrieved November 1, 2007 from: http://www.igreenbuild.com/cd_1706.aspx

Schendler, A. and Udall, R. (2005). LEEDing us astray? Retieved November 1, 2007 from: http:// www.grist.org/comments/soapbox/2005/10/26/leed/

Soloman, N.B. (2005). How is LEED faring after five years in use? Architectural Record 193(6), 135-138,140,142.

Stromberg, M. (2007). Illinois to offer incentives for LEED-certified developments. Planning 73(10), 53-53, 2/3. 